\title{
Announcements
}

\section{MEMBERS OF UNDERREPRESENTED GROUPS: REVIEWERS FOR JOURNAL MANUSCRIPTS WANTED}

If you are interested in reviewing manuscripts for APA journals, the APA Publications and Communications Board would like to invite your participation. Manuscript reviewers are vital to the publication process. As a reviewer, you would gain valuable experience in publishing. The P\&C Board is particularly interested in encouraging members of underrepresented groups to participate more in this process.

If you are interested in reviewing manuscripts, please write to Leslie Cameron at the address below. Please note the following important points:

- To be selected as a reviewer, you must have published articles in peerreviewed journals. The experience of publishing provides a reviewer with the basis for preparing a thorough, objective evaluative review.

- To select the appropriate reviewers for each manuscript, the editor needs detailed information. Please include with your letter your vita. In your letter, please identify which APA journal you are interested in and describe your area of expertise. Be as specific as possible. For example, "social psychology" is not sufficient-you would need to specify "social cognition" or "attitude change" as well.

- Reviewing a manuscript takes time. If you are selected to review a manuscript, be prepared to invest the necessary time to evaluate the manuscript thoroughly.

Write to Leslie Cameron, Journals Office, APA, 1400 N. Uhle Street, Arlington, Virginia 22201.

\section{IN PRESS}

The following manuscripts are in press and will be published in the coming issues of Law and Human Behavior. The titles and author addresses are provided here so that readers can obtain prepublication copies from the authors.

Baskin, D. R., \& Sommers, I. Ideology and Discourse: Some Differences Between State-Planned and Community-Based Justice. (Deborah R. Baskin, John Jay College of Criminal Justice, New York, New York 10019) 
Kramer, T. H., Buckhout, R., \& Eugenio, P. Weapon Focus, Arousal, and Eyewitness Memory. (Thomas Kramer, 401 State St., Apt. P-207, Portsmouth, New Hampshire 03801)

Smith, V. L. The Feasibility and Utility of Pretrial Instruction in the Law. (Vicki Smith, Department of Psychology, Northwestern University, Evanston, Illinois 60201)

Horowitz, I. A., \& K. S. Bordens. An Experimental Investigation of Procedural Issues in Complex Tort Trials. (Irwin Horowitz, Department of Psychology, The University of Toledo, 2801 Bancroft St., Toledo, Ohio 43606)

Stalans, L. J., \& Diamond, S. S. Lay Perceptions of Judicial Leniency. (Loretta Stalans, American Bar Foundation, 750 N. Lake Shore Drive, Chicago, Illinois 60611) 